\title{
Emergence of Bacterial Soft Rot in Cucumber Caused by Pectobacterium carotovorum subsp. brasiliense in China
}

Xianglong Meng, Institute of Vegetables and Flowers, Chinese Academy of Agricultural Sciences, Beijing 100081; and Department of Plant Pathology, China Agricultural University, Beijing 100094; Ali Chai, Yanxia Shi, and Xuewen Xie, Institute of Vegetables and Flowers, Chinese Academy of Agricultural Sciences; Zhanhong Ma, Department of Plant Pathology, China Agricultural University; and Baoju Li, Institute of Vegetables and Flowers, Chinese Academy of Agricultural Sciences

\begin{abstract}
During 2014 to 2015, a devastating bacterial soft rot on cucumber stems and leaves occurred in Shandong, Shanxi, Hebei, Henan, and Liaoning provinces of China, resulting in serious economic losses for cucumber production. The gummosis emerged on the surface of leaves, stems, petioles, and fruit of cucumber. The basal stem color was dark brown and the stem base turned to wet rot. Yellow spots and wet rot emerged at the edge of the infected cucumber leaves and gradually infected the leaf centers. In total, 45 bacterial strains were isolated from the infected tissues. On the basis of phenotypic properties of morphology, physiology, biochemistry, and

16S ribosomal RNA gene sequence analysis, the pathogen was identified as Pectobacterium carotovorum. Multilocus sequence analysis confirmed that the isolates were $P$. carotovorum subsp. brasiliense, and the pathogens fell in clade II. The pathogenicity of isolated bacteria strains was confirmed. The strains reisolated were the same as the original. The host range test confirmed that strains had a wide range of hosts. As far as we know, this is the first report of cucumber stem soft rot caused by $P$. carotovorum subsp. brasiliense in China as well as in the world, which has a significant economic impact on cucumber production.
\end{abstract}

Cucumber (Cucumis sativus L.) is a widely cultivated plant in the gourd family Cucurbitaceae. Statistically, China is the largest cucumber producer in the world, with 1.17 million $\mathrm{hm}^{2}$ of harvested area and 54.36 million tons in 2013 (http://faostat3.fao. org/download/Q/QC/E). However, during the growth process, cucumber plants are susceptible to many diseases. During 2014 to 2015, an outbreak of cucumber bacterial soft rot occurred in Shandong, Shanxi, Hebei, Henan, and Liaoning provinces in China. The disease incidence varied from 15 to $50 \%$ in different fields, causing 20 to $30 \%$ yield losses.

Bacterial soft rot was thought to be caused by Pectobacterium carotovorum, which can macerate parenchymatous plant tissues by producing a mass of pectic enzymes (Pérombelon and Kelman 1980) and causes soft rot, blackleg, and wilt in many vegetable crops and ornamental plant species (Hauben et al. 1998; Pérombelon 2002; Toth et al. 2003). P. carotovorum consist of three valid names: P. carotovorum subsp. carotovorum (Gardan et al. 2003), P. carotovorum subsp. odoriferum (Gallois et al. 1992), and P. carotovorum subsp. brasiliense (Duarte et al. 2004). P. carotovorum subsp. brasiliense was first reported as pathogenic bacteria of potato black rot in Brazil (Duarte et al. 2004) and, recently, has been found as the pathogen of paprika in Korea (Choi and Kim 2013) and potato in the United States, Israel, Kenya, New Zealand, Switzerland, and South Africa (de Werra et al. 2015; Marquez-Villavicencio et al. 2011; Onkendi et al. 2014; Panda et al. 2012; Pérombelon 2002; van der Merwe et al. 2010). However, there is no report about $P$. carotovorum subsp. brasiliense causing bacterial soft rot in cucumber.

The biochemical or genetic characteristics of $P$. carotovorum strains show diversity among the same subspecies (Nabhan et al. 2012); thus, identification of these pathogens is difficult when only using phenotypic, biochemical studies or $16 \mathrm{~S}$ ribosomal RNA

Corresponding author: B. Li; E-mail: libaoju@caas.cn

X. Meng and A. Chai contributed equally to this work and are considered co-first authors.

Accepted for publication 14 July 2016.

C 2017 The American Phytopathological Society
(rRNA) sequence analysis. In recent years, classification studies based on multilocus sequence analysis (MLSA) were used to identify P. carotovorum strains (Nabhan et al. 2011; Onkendi et al. 2014), because MLSA may provide a better understanding of speciation events in bacteria (Hanage et al. 2006) and it was proved to be one of the most reliable methods for differentiating $P$. carotovorum strains (Kim et al. 2009).

This study aimed to isolate and identify the bacterium associated with recently occurred soft rot on cucumber in Shandong, Shanxi, Hebei, Henan, and Liaoning provinces of China. Different types of analyses, such as physiological and molecular analyses, MLSA of housekeeping genes, and pathogenicity assays in cucumber and different plant hosts were used to determine the validity of the pathogen.

\section{Materials and Methods}

Sample collection and strain isolation. A field symptom survey was carried out on cucumber in 20 greenhouses in Shandong, Shanxi, Hebei, Henan, and Liaoning provinces in China from November 2014 to March 2015. Approximately 68 samples (including $15 \mathrm{cu}-$ cumber fruit, 22 stems, and 31 leaves) which showed gummosis, soft rot, or yellow spots were collected from 18 greenhouses. In all, 45 samples (9 fruit, 16 stems, and 24 leaves) were used for isolation and identification, and the other 17 samples (4 fruit, 6 stems, and 7 leaves) were deposited at the Institute of Vegetables and Flowers, Chinese Academy of Agricultural Sciences as specimens for future reference. To isolate the pathogens, infected tissues were surface sterilized for $30 \mathrm{~s}$ in $75 \%$ ethanol, rinsed in sterile distilled water, and then ground with a sterile scalpel in $1 \mathrm{ml}$ of sterile distilled water. The ground tissue was soaked for $3 \mathrm{~min}$, and $10 \mu \mathrm{l}$ of liquid suspension was streaked on nutrient agar medium. In total, 45 isolates with the same colony morphology were obtained from infected tissues, and nine strains were randomly selected for the following studies (Table 1).

Phenotypic and biochemical characterization. Carbon source utilization studies were carried out using the Microlog system (Biolog Inc.). Nine selected strains were assayed for the oxidation of the 95 carbon sources in the GN2 microplates, as suggested by the manufacturer. Microplates were inoculated with $150 \mu$ l of suspension per well at $27^{\circ} \mathrm{C}$. Additionally, all strains were characterized by standard tests commonly used for pectolytic Pectobacterium spp. and included a test for pectolytic activity on crystal violet pectate 
(CVP) medium, acid production from maltose and $\alpha$-methyl-Dglucoside, reducing substances from sucrose, growth at $37^{\circ} \mathrm{C}$, erythromycin sensitivity (Duarte et al. 2004), tolerance to $5 \% \mathrm{NaCl}$, lactose fermentation, and gas production from D-glucose (Nabhan et al. 2012).

16S rRNA gene sequence analysis. The universal primers $27 \mathrm{~F}$ (5'-AGA GTT TGA TCC TGG CTC AG-3') and 1492R (5'-ACG
GCT ACC TTG TTA CGA CTT-3') were used to amplify the $16 \mathrm{~S}$ rRNA gene sequences of nine isolated strains. Polymerase chain reaction (PCR) was performed using a $50-\mu 1$ reaction mix containing $2 \mu \mathrm{l}$ of each primer, $25 \mu \mathrm{l}$ of master mix (Biomed), $19 \mu \mathrm{l}$ of $\mathrm{H}_{2} \mathrm{O}$, and $2 \mu \mathrm{l}$ of DNA template $\left(5 \mu \mathrm{g} \mu \mathrm{l}^{-1}\right)$. The PCR amplification program consisted of an initial denaturation at $95^{\circ} \mathrm{C}$ for $10 \mathrm{~min} ; 35$

Table 1. Source of strains isolated from cucumber in China and its pathogenicity assays for different plant species

\begin{tabular}{|c|c|c|c|c|c|c|c|}
\hline \multirow[b]{2}{*}{ Isolates } & \multicolumn{4}{|c|}{ Source of isolation } & \multicolumn{3}{|c|}{ Pathogenicity $^{\mathbf{a}}$} \\
\hline & Tissue & Cultivar & Loc $^{b}$ & Data collected & Zucchini & Watermelon & Balsam pear \\
\hline HG1501090302 & Leaf & Zhongnong No. 6 & SD & January 2015 & + & + & + \\
\hline HG1501090303 & Fruit & Zhongnong No. 6 & SD & January 2015 & + & + & + \\
\hline HG1501090304 & Stem & Fengyan No. 3 & SX & November 2014 & + & + & + \\
\hline HG1501090305 & Stem & Fengyan No. 3 & SX & November 2014 & + & + & + \\
\hline HG1501090306 & Fruit & Deruite 721 & SX & February 2015 & + & + & + \\
\hline HG1501090307 & Stem & Deruite 233 & $\mathrm{HN}$ & December 2014 & + & + & + \\
\hline HG1501090308 & Leaf & Deruite 233 & $\mathrm{HN}$ & December 2014 & + & + & + \\
\hline HG1501090309 & Fruit & Unknown & $\mathrm{HB}$ & February 2015 & + & + & + \\
\hline HG1501090310 & Stem & Unknown & $\mathrm{LN}$ & March 2015 & + & + & + \\
\hline
\end{tabular}

a Symbols: + represents infection and disease symptoms and - represents no disease symptoms.

b Locations: $\mathrm{SD}=$ Shandong; HB = Hebei; $\mathrm{SX}=$ Shanxi; HN = Henan; and LN = Liaoning province.

Table 2. GenBank accession numbers for the eight genes ( $a c n A, g a b A, i c d A, m d h, m t l D$, pgi, proA, and $r p o S)$ of nine randomly selected strains and reference Pectobacterium spp. strains

\begin{tabular}{|c|c|c|c|c|c|c|c|c|}
\hline \multirow[b]{2}{*}{ Strain $^{\mathbf{a}}$} & \multicolumn{8}{|c|}{ GenBank accession numbers } \\
\hline & $\operatorname{acn} A$ & $g a b A$ & $i c d A$ & $m d h$ & $m t l D$ & pgi & proA & rpos \\
\hline \multicolumn{9}{|l|}{ brasiliense } \\
\hline 8 & JF926768.1 & JF926778.1 & JF926788.1 & JF926798.1 & JF926808.1 & JF926818.1 & JF926828.1 & JF926838.1 \\
\hline 213 & JF926771.1 & JF926781.1 & JF926791.1 & JF926801.1 & JF926811.1 & JF926821.1 & JF926831.1 & JF926841.1 \\
\hline 371 & JF926770.1 & JF926780.1 & JF926790.1 & JF926800.1 & JF926810.1 & JF926820.1 & JF926830.1 & JF926840.1 \\
\hline $212^{\mathrm{T}}$ & JF926769.1 & JF926779.1 & JF926789.1 & JF926799.1 & JF926809.1 & JF926819.1 & JF926829.1 & JF926839.1 \\
\hline SCRI1073 & HM156787 & HM156848 & HM156910 & HM156971 & HM157033 & HM157090 & HM157157 & HM157201 \\
\hline 1001 & JF926767.1 & JF926777.1 & JF926787.1 & JF926797.1 & JF926807.1 & JF926817.1 & JF926827.1 & JF926837.1 \\
\hline 1009 & JF926766.1 & JF926776.1 & JF926786.1 & JF926796.1 & JF926806.1 & JF926816.1 & JF926826.1 & JF926836.1 \\
\hline A17 & HM156764 & HM156824 & HM156885 & HM156946 & HM157008 & HM157070 & HM157132 & HM157194 \\
\hline $\mathrm{C} 18$ & HM156768 & HM156828 & HM156889 & HM156950 & HM157012 & HM157074 & HM157136 & HM157198 \\
\hline \multicolumn{9}{|l|}{ carotovorum } \\
\hline JKI4.3.8 & HM156790 & HM156849 & HM156911 & HM156972 & HM157036 & HM157092 & HM157158 & HM157204 \\
\hline C412.4 & HM156784 & HM156843 & HM156905 & HM156966 & HM157028 & HM157091 & HM157152 & HM157227 \\
\hline C137 & HM156769 & HM156829 & HM156890 & HM156951 & HM157013 & HM157075 & HM157137 & HM157210 \\
\hline C142.2 & HM156773 & HM156833 & HM156894 & HM156955 & HM157017 & HM157079 & HM157141 & HM157214 \\
\hline C267 & HM156777 & HM156836 & HM156898 & HM156959 & HM157021 & HM157083 & HM157145 & HM157218 \\
\hline $\mathrm{C} 3$ & HM156767 & HM156827 & HM156888 & HM156949 & HM157011 & HM157073 & HM157135 & HM157197 \\
\hline C338 & HM156780 & HM156839 & HM156901 & HM156962 & HM157024 & HM157086 & HM157148 & HM157221 \\
\hline A10.1 & HM156761 & HM156821 & HM156882 & HM156943 & HM157005 & HM157067 & HM157129 & HM157191 \\
\hline A18 & HM156765 & HM156825 & HM156886 & HM156947 & HM157009 & HM157071 & HM157133 & HM157195 \\
\hline M30 & HM156785 & HM156844 & HM156906 & HM156967 & HM157029 & HM157099 & HM157153 & HM157199 \\
\hline $\mathrm{C} 144$ & HM156775 & HM156835 & HM156896 & HM156957 & HM157019 & HM157081 & HM157143 & HM157216 \\
\hline CFBP2046 $^{\mathrm{T}}$ & JF926762.1 & JF926772.1 & JF926782.1 & JF926792.1 & JF926802.1 & JF926812.1 & JF926822.1 & JF926832.1 \\
\hline SCRI2 & HM156788 & HM156846 & HM156908 & HM156969 & HM157031 & HM157104 & HM157155 & HM157202 \\
\hline \multicolumn{9}{|l|}{ odoriferum } \\
\hline CFBP1878T & JF926763.1 & JF926773.1 & JF926783.1 & JF926793.1 & JF926803.1 & JF926813.1 & JF926823.1 & JF926833.1 \\
\hline JKI582 & HM156799 & HM156857 & HM156919 & HM156980 & HM157042 & HM157102 & HM157165 & HM157229 \\
\hline NB1892 & HM156798 & HM156858 & HM156920 & HM156981 & HM157043 & HM157103 & HM157166 & HM157230 \\
\hline \multicolumn{9}{|l|}{ Cucumber } \\
\hline HG1501090302 & KX010008 & KX010017 & KX010026 & KX010035 & KX010044 & KX010062 & KX010071 & KX010053 \\
\hline HG1501090303 & KX010009 & KX010018 & KX010027 & KX010036 & KX010045 & KX010063 & KX010072 & KX010054 \\
\hline HG1501090304 & KX010010 & KX010019 & KX010028 & KX010037 & KX010046 & KX010064 & KX010073 & KX010055 \\
\hline HG1501090305 & KX010011 & KX010020 & KX010029 & KX010038 & KX010047 & KX010065 & KX010074 & KX010056 \\
\hline HG1501090306 & KX010012 & KX010021 & KX010030 & KX010039 & KX010048 & KX010066 & KX010075 & KX010057 \\
\hline HG1501090307 & KX010013 & KX010022 & KX010031 & KX010040 & KX010049 & KX010067 & KX010076 & KX010058 \\
\hline HG1501090308 & KX010014 & KX010023 & KX010032 & KX010041 & KX010050 & KX010068 & KX010077 & KX010059 \\
\hline HG1501090309 & KX010015 & KX010024 & KX010033 & KX010042 & KX010051 & KX010069 & KX010078 & KX010060 \\
\hline HG1501090310 & KX010016 & KX010025 & KX010034 & KX010043 & KX010052 & KX010070 & KX010079 & KX010061 \\
\hline
\end{tabular}

\footnotetext{
${ }^{\mathrm{a}}$ Strain designations: brasiliense $=$ Pectobacterium carotovorum subsp. brasiliense, carotovorum $=P$. carotovorum subsp. carotovorum, odoriferum $=P$. car
} otovorum subsp. odoriferum, and Cucumber = strains isolated from cucumber. 
cycles of $95^{\circ} \mathrm{C}$ for $30 \mathrm{~s}, 55^{\circ} \mathrm{C}$ for $30 \mathrm{~s}$, and $72^{\circ} \mathrm{C}$ for $45 \mathrm{~s}$; and a final 10 -min elongation step at $72^{\circ} \mathrm{C}$ in a $\mathrm{S} 1000$ Thermal Cycler (BioRad). Amplified fragments were detected by electrophoresis on a $1.5 \%$ agarose gel and purified from the gel using a gel extraction kit (TIANGEN). Sequencing was performed by Biomad (BigDye
Terminator ready reaction mix v31; Applied Biosystems). Sequences were submitted to GenBank under accession numbers KU997676 to KU997684. The 16S rRNA sequences of 9 isolated strains and 18 reference strains were aligned in MEGA 6.0 software. Phylogenetic analysis was performed using the maximum-likelihood method

Table 1. (continued from preceding page)

\begin{tabular}{|c|c|c|c|c|c|c|c|c|c|c|}
\hline \multicolumn{11}{|c|}{ Pathogenicity $^{\mathbf{a}}$} \\
\hline Loofah & Chinese cabbage & Mustard & Broccoli & Radish & Cabbage & Pepper & Tomato & Potato & Spinach & Celery \\
\hline- & - & + & + & + & + & + & + & + & + & + \\
\hline - & - & + & + & + & + & + & + & + & + & + \\
\hline - & - & + & + & + & + & + & + & + & + & + \\
\hline - & - & + & + & + & + & + & + & + & + & + \\
\hline - & - & + & + & + & + & + & + & + & + & + \\
\hline- & - & + & + & + & + & + & + & + & + & + \\
\hline- & - & + & + & + & + & + & + & + & + & + \\
\hline- & - & + & + & + & + & + & + & + & + & + \\
\hline- & - & + & + & + & + & + & + & + & + & + \\
\hline
\end{tabular}

Table 3. Primers for amplifying eight conserved housekeeping genes

\begin{tabular}{|c|c|c|c|c|c|}
\hline Gene & Full name & $\begin{array}{c}\text { Sequence } \\
\text { length (bp) }\end{array}$ & Primer name & Primer sequence & Reference \\
\hline \multirow[t]{2}{*}{$\operatorname{acn} A$} & Aconitate hydrase 1 & 300 & $\operatorname{acn} A 3 \mathrm{~F}$ & CMAGRGTRTTRATGCARGAYTTTAC & Ma et al. 2007 \\
\hline & $\ldots$ & $\ldots$ & $\operatorname{acn} A 3 R$ & GATCATGGTGGTRTGSGARTCVGT & $\ldots$ \\
\hline \multirow[t]{2}{*}{ gapA } & Glyceraldehyde-3-phosphate dehydrogenase A & 450 & gapA326F & ATCTTCCTGACCGACGAAACTGC & Ma et al. 2007 \\
\hline & $\ldots$ & $\ldots$ & gapA845R & ACGTCATCTTCGGTGTAACCCAG & .. \\
\hline \multirow[t]{2}{*}{$i c d A$} & Isocitrate dehydrogenase, specific for NADP+ & 520 & icdA400F & GGTGGTATCCGTTCTCTGAACG & Ma et al. 2007 \\
\hline & $\ldots$ & $\ldots$ & icdA977R & TAGTCGCCGTTCAGGTTCATACA & $\ldots$ \\
\hline \multirow[t]{2}{*}{$m d h$} & Malate dehydrogenase & 460 & mdh86F & CCCAGCTTCCTTCAGGTTCAGA & Ma et al. 2007 \\
\hline & $\ldots$ & $\ldots$ & mdh628R & CTGCATTCTGAATACGTTTGGTCA & $\ldots$ \\
\hline \multirow[t]{2}{*}{$m t l D$} & Mannitol-1-phosphate dehydrogenase & 390 & mtlD146F & GGCCGGTAATATCGGCCGTGG & Ma et al. 2007 \\
\hline & $\ldots$ & $\cdots$ & mtlD650R & CATTCGCTGAAGGTTTCCACCGT & 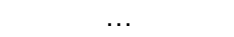 \\
\hline \multirow[t]{2}{*}{$p g i$} & Glucose-6-phosphate isomerase & 520 & pgi815F & TGGGTCGGCGGCCGTTACTC & Ma et al. 2007 \\
\hline & $\ldots$ & $\ldots$ & pgi1396R & TGCCTTCGAATACTTTGAACGGC & $\cdots$ \\
\hline \multirow[t]{2}{*}{ proA } & $\gamma$-Glutamylphosphate reductase & 630 & proAF1 & CGGYAATGCGGTGATTCTGCG & Ma et al. 2007 \\
\hline & $\ldots$ & $\ldots$ & proAR1 & GGGTACTGACCGCCACTTC & $x_{-1}+2+2$ \\
\hline \multirow[t]{2}{*}{ rpos } & RNA polymerase subunit $\sigma$ factor 38 & 880 & rpoS1 & ATGAGCCAAAGTACGCTGAA & Waleron et al. 2002 \\
\hline & $\ldots$ & $\ldots$ & $\operatorname{rpoS} 2$ & ACCTGAATCTGACGAACACG & $\ldots$ \\
\hline
\end{tabular}
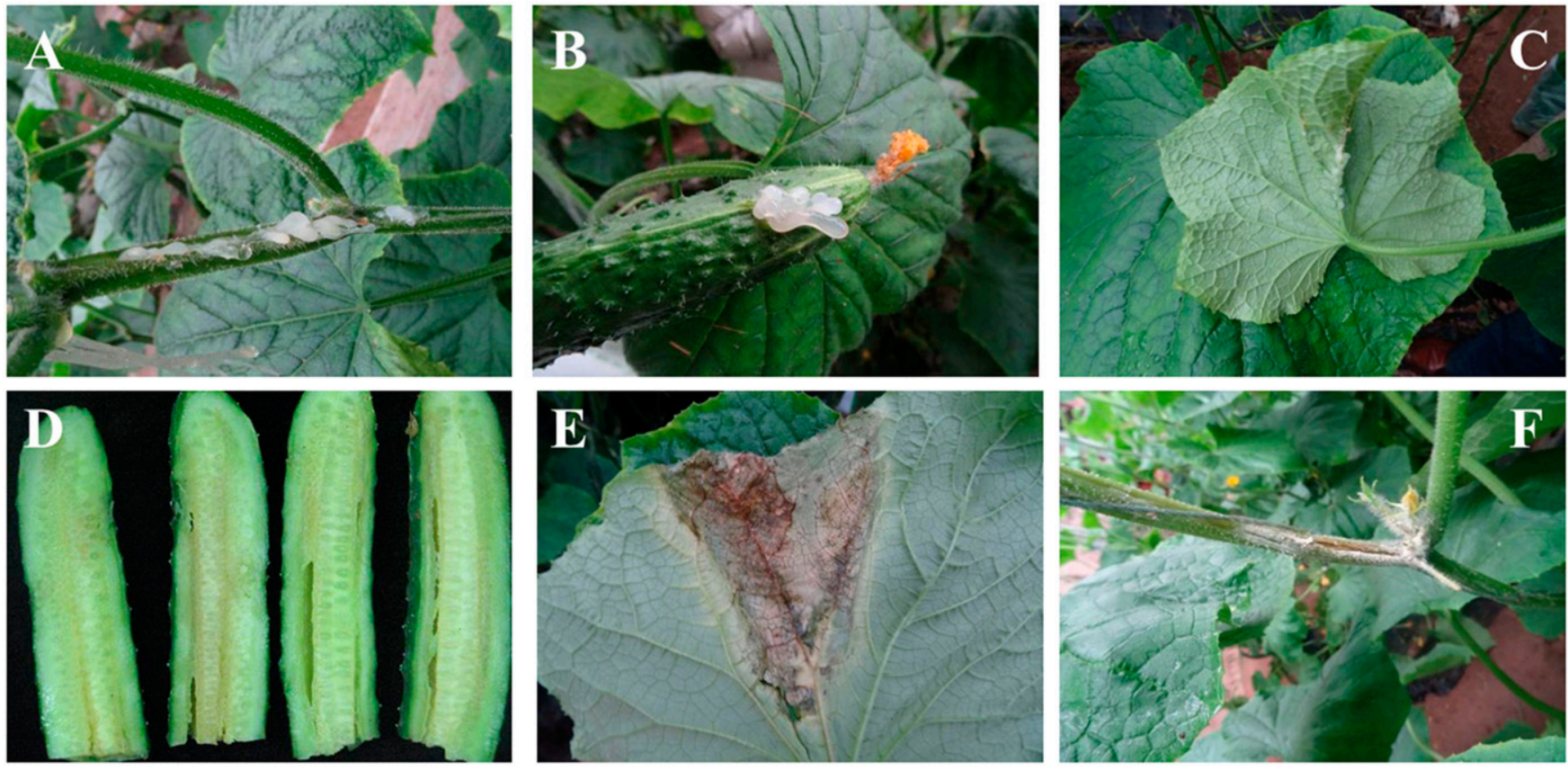

Fig. 1. Symptoms of the soft rot disease of cucumber caused by Pectobacterium carotovorum subsp. brasiliense. A, B, and C, Whitish liquid produced on the surface of the stems, fruit, and leaves, respectively; D, E, and F, symptoms of the infected fruit, leaves, and stems, respectively. 
based on the Tamura-Nei model with the number of bootstrap replicates set at 1,000 (Tamura and Nei 1993).

MLSA. Eight informative housekeeping genes ( $m t l D, a c n A$, icdA, $m d h, p g i, g a b A, p r o A$, and $r p o S$ ) were used in the MLSA. Publically available housekeeping gene sequences of $25 P$. carotovorum strains (Ma et al. 2007; Nabhan et al. 2011) were retrieved from the National Center for Biotechnology Information GenBank (Table 2). For the nine strains isolated from cucumber in China, PCR amplification of eight conserved housekeeping gene fragments was carried out following previously described methods (Nabhan et al. 2011). The primers of eight conserved housekeeping genes are listed in Table 3. Sequencing was carried out by Biomad (BigDye Terminator ready reaction mix v31; Applied Biosystems) and sequences were submitted to GenBank under accession numbers KX010008 to KX010079 (Table 2). The housekeeping gene sequences were aligned using CLUSTAL-W in MEGA, version 6.0 (Tamura et al. 2011). The phylogenetic analysis was conducted using all nucleotide sites of each partial gene sequence: $m t l D$ (390 bp), acnA (300 bp), icdA (520 bp), mdh (460 bp), pgi (520 bp), gapA (450 bp), proA (630 bp), and rpoS (880 bp). The informative maximum-likelihood method based on the Tamura-Nei model (Tamura and Nei 1993) was constructed in MEGA with a bootstrapping test of 1,000 replications.

Pathogenicity and host range test. To confirm Koch's postulates, fruit, stems, and leaves of cucumber plants ('Zhongnong No. 16 ') were surface sterilized with $1 \% \mathrm{NaOCl}$ and inoculated with $P$. carotovorum subsp. brasiliense strains. Cucumber fruit were stab inoculated with $10 \mu \mathrm{l}$ of bacterial suspensions $\left(10^{7} \mathrm{CFU} / \mathrm{ml}\right)$ of HG1501090303, HG1501090306, and HG1501090309 (isolated from fruit) obtained from Luria-Bertani (LB) broth (containing $10 \mathrm{~g}$ of tryptone, $5 \mathrm{~g}$ of yeast extract, and $10 \mathrm{~g}$ of $\mathrm{NaCl}, \mathrm{pH} \mathrm{7.4,} \mathrm{in} 1$ liter of water). Cucumber stems were stab inoculated with $10 \mu \mathrm{l}$ of bacterial suspensions $\left(10^{7} \mathrm{CFU} / \mathrm{ml}\right)$ of HG1501090304, HG1501090305, HG1501090307, and HG1501090310 (isolated from stems). Cucumber leaves were spray inoculated with $10 \mathrm{ml}$ of bacterial suspensions $\left(10^{7} \mathrm{CFU} / \mathrm{ml}\right.$ ) of HG1501090302 and HG1501090308 (isolated from leaves). Each fruit or stem was stabbed at three points, and the distance between two adjacent stabbed points was $1 \mathrm{~cm}$. Each leaf was sprayed on the surface using the bacterial suspension. Sterilized distilled water was used for negative control inoculations. Inoculated fruit and seedlings were maintained in a glass cabinet at 26 to $30^{\circ} \mathrm{C}$ with $98 \%$ humidity for $48 \mathrm{~h}$. After that, the inoculated fruit and seedlings were moved out and incubated in a greenhouse maintained at 15 to $17^{\circ} \mathrm{C}$ (night) and 26 to $28^{\circ} \mathrm{C}$ (day) under natural daylight conditions and monitored daily for presence or absence of symptoms. The fruit and seedlings with typical symptoms of soft rot were reisolated on LB agar mediums, and the morphological and physiological characteristics of the strains were compared with the original bacteria. The inoculation experiment was repeated three times, and each repeat included four fruit and seedlings.

The host ranges of nine randomly selected strains were tested with different plant species. Each inoculum was stabbed into seedlings or tubers of 15 species of plants, including 5 species of Cucurbitaceae (cucumber, zucchini, watermelon, balsam pear, and loofah), 5 species of Brassicaceae (Chinese cabbage, mustard, broccoli, radish, and cabbage), 3 species of Solanaceae (green pepper, tomato, and potato), 1 species of Amaranthaceae (spinach), and 1 species of Apiaceae (celery) (Table 1). Individual seedlings of potted plants (3 weeks old) or tubers from harvested plants were stab inoculated with $10 \mu \mathrm{l}$ of bacterial suspensions $\left(10^{7} \mathrm{CFU} / \mathrm{ml}\right)$ of nine randomly selected strains obtained from LB broth. Each seedling or tube was stabbed at three points, and the distance between two adjacent stabbed points was $1 \mathrm{~cm}$. Controls were inoculated with a sterile toothpick dipped with sterilized water. The inoculum plants were treated as described above.

Table 4. Phenotypic characteristics of Pectobacterium carotovorum subsp. brasiliense and $P$. carotovorum subsp. carotovorum reference strains and nine randomly selected strains isolated from cucumber in China

\begin{tabular}{|c|c|c|c|c|c|c|c|c|c|c|c|}
\hline \multirow[b]{2}{*}{ Characteristic } & \multicolumn{11}{|c|}{ Responses of strains ${ }^{a}$} \\
\hline & $212^{T}$ & $21^{T}$ & 1 & 2 & 3 & 4 & 5 & 6 & 7 & 8 & 9 \\
\hline Phosphatase & - & - & - & - & - & - & - & - & - & - & - \\
\hline Acid from $\alpha$-methyl glucoside & + & - & + & + & + & + & + & + & + & + & + \\
\hline Tolerance of $5 \% \mathrm{NaCl}$ & + & + & + & + & + & + & + & + & + & + & + \\
\hline Growth at CVP medium ${ }^{b}$ & + & + & + & + & + & + & + & + & + & + & + \\
\hline Growth at $37^{\circ} \mathrm{C}$ & + & + & + & + & + & + & + & + & + & + & + \\
\hline Acid production from glucose & + & - & + & + & + & + & + & + & + & + & + \\
\hline Reducing substances from sucrose & + & - & + & + & + & + & + & + & + & + & + \\
\hline Acid production from maltose & + & - & + & + & + & + & + & + & + & + & + \\
\hline \multicolumn{12}{|l|}{ Utilization of } \\
\hline Acetic acid & + & + & + & + & + & + & + & + & + & + & + \\
\hline Cellobiose & + & + & + & + & + & + & + & + & + & + & + \\
\hline D-arabitol & - & - & - & - & - & - & - & - & - & - & - \\
\hline 2'-Deoxyadenosine & - & + & - & - & - & - & - & - & - & - & - \\
\hline D-glucosaminic acid & - & - & - & - & - & - & - & - & - & - & - \\
\hline D-glucuronic acid & - & - & - & - & - & - & - & - & - & - & - \\
\hline D,1-lactic acid & + & + & - & - & - & - & - & - & - & - & - \\
\hline D-melibiose & + & + & + & + & + & + & + & + & + & + & + \\
\hline D-sorbitol & + & - & + & + & + & + & + & + & + & + & + \\
\hline Glucose-1-phosphate & - & + & - & - & - & - & - & - & - & - & - \\
\hline Inosine & - & + & - & - & - & - & - & - & - & - & - \\
\hline L-glutamic acid & - & + & - & - & - & - & - & - & - & - & - \\
\hline Maltose & - & + & - & - & - & - & - & - & - & - & - \\
\hline Succinamic acid & + & + & + & + & + & + & + & + & + & + & + \\
\hline Thymidine & + & + & + & + & + & + & + & + & + & + & + \\
\hline Tween-40 & - & + & - & - & - & - & - & - & - & - & - \\
\hline Tween-80 & - & + & - & - & - & - & - & - & - & - & - \\
\hline Uridine & + & + & + & + & + & + & + & + & + & + & + \\
\hline
\end{tabular}

${ }^{a}$ Numbers $212^{\mathrm{T}}$ and $21^{\mathrm{T}}$ are reference strains of $P$. carotovorum subsp. brasiliense and $P$. carotovorum subsp. carotovorum, respectively. Numbers 1 to 9 represent nine randomly selected strains isolated from cucumber in China: $1=$ HG1501090302, $2=$ HG1501090303, $3=$ HG1501090304, 4 = HG1501090305, 5= HG1501090306, 6 = HG1501090307, 7 = HG1501090308, 8 = HG1501090309, and 9 = HG1501090310. Symbols: + and - indicate positive and negative responses, respectively, for the tested strain.

${ }^{\mathrm{b}}$ Crystal violet pectate medium. 
The inoculation experiment was repeated three times, and each repeat included four plants or tubes.

\section{Results}

Symptoms of infected cucumber plants and bacterial isolation. Surveys of cucumber soft rot disease were conducted from November 2014 to March 2015 in Shandong, Shanxi, Hebei, Henan, and Liaoning provinces of Chin. This disease was found in $90 \%$ of 20 surveyed greenhouses, and the disease incidence ranged from 20 to $50 \%$ in different regions. Symptoms on cucumber plants initially appeared as whitish, thick liquid produced on the surface of the infected tissues (Fig. 1A, B, and C) and water soaking in the infected stems. Later symptoms present as brown rot in the fruit (Fig. 1D) and wet rot on the edge or center of the leaves (Fig. 1E). With the development of the infection, the stems gradually cracked longitudinally (Fig. 1F) and showed soft rot symptoms. In total, 45 morphologically similar isolates were obtained from 45 diseased tissue samples, and the frequency of recovery of isolates from plated tissues was $100 \%$. Nine strains were randomly selected for later studies (Table 1).

Biochemical and physiological characterizations. The biochemical and physiological characterizations of nine strains are listed in Table 4. All strains were able to grow at 28 and $37^{\circ} \mathrm{C}$, showed tolerance of $5 \% \mathrm{NaCl}$, and formed pits on $\mathrm{CVP}$ media. All strains are gram-negative and facultative anaerobes. Based on biological analysis, 35 of the 95 carbon sources tested can be metabolized by all of the strains. All strains can produce acid from $\alpha$-methyl glucoside, glucose, and maltose and utilize acetic acid, acetic acid, cellobiose, d-melibiose, d-sorbitol, succinamic acid, and thymidine. These characteristics are consistent with published data for $P$. carotovorum subsp. brasiliense (Duarte et al. 2004; van der Merwe et al. 2010).

$16 S$ rRNA gene analysis. The DNA sequences of the partial 16S rRNA region from these nine representative isolates were sequenced and aligned for phylogenetic analysis. Amplification of the $16 \mathrm{~S}$ rRNA gene generated a 1,400-bp sequence of the nine isolate strains. The phylogenetic analysis based on 16S rRNA divided the 27 strains into four levels of similarity (Fig. 2). The selected strains isolated from cucumber in China share $99 \%$ identity with $P$. carotovorum subsp. brasiliense, and grouped together with strains of $P$. carotovorum subsp. brasiliense and a partial strain of $P$. carotovorum subsp. carotovorum. There was no apparent relation between the clustering of isolates and strains of $P$. wasabiae, $P$. atrosepticum, $P$. carotovorum subsp. odoriferum, Dickeya zeae, or Pseudomonas syringae pv. lachrymans. This result indicates that the strain isolates from cucumber in China belong to Pectobacterium carotovorum.

MLSA analysis. To further characterize the subspecies level of the selected strains isolated from cucumber in China, eight housekeeping genes of $a c n A, \operatorname{gapA}, i c d A, m d h, m t l D, p g i$, and $p r o A$ from nine isolate strains and 25 related taxa were concatenated and used for MLSA (Fig. 3). The MLSA revealed that the P. carotovorum subsp. brasiliense strains grouped into two clades, I and II. Clade I comprised strains from Brazil and Peru, including the type strain $212^{\mathrm{T}}$, while strains in clade II were from Europe, Asia, and North America, which was consistent with a previous study (Nabhan et al. 2012). The nine selected strains isolated from cucumber in

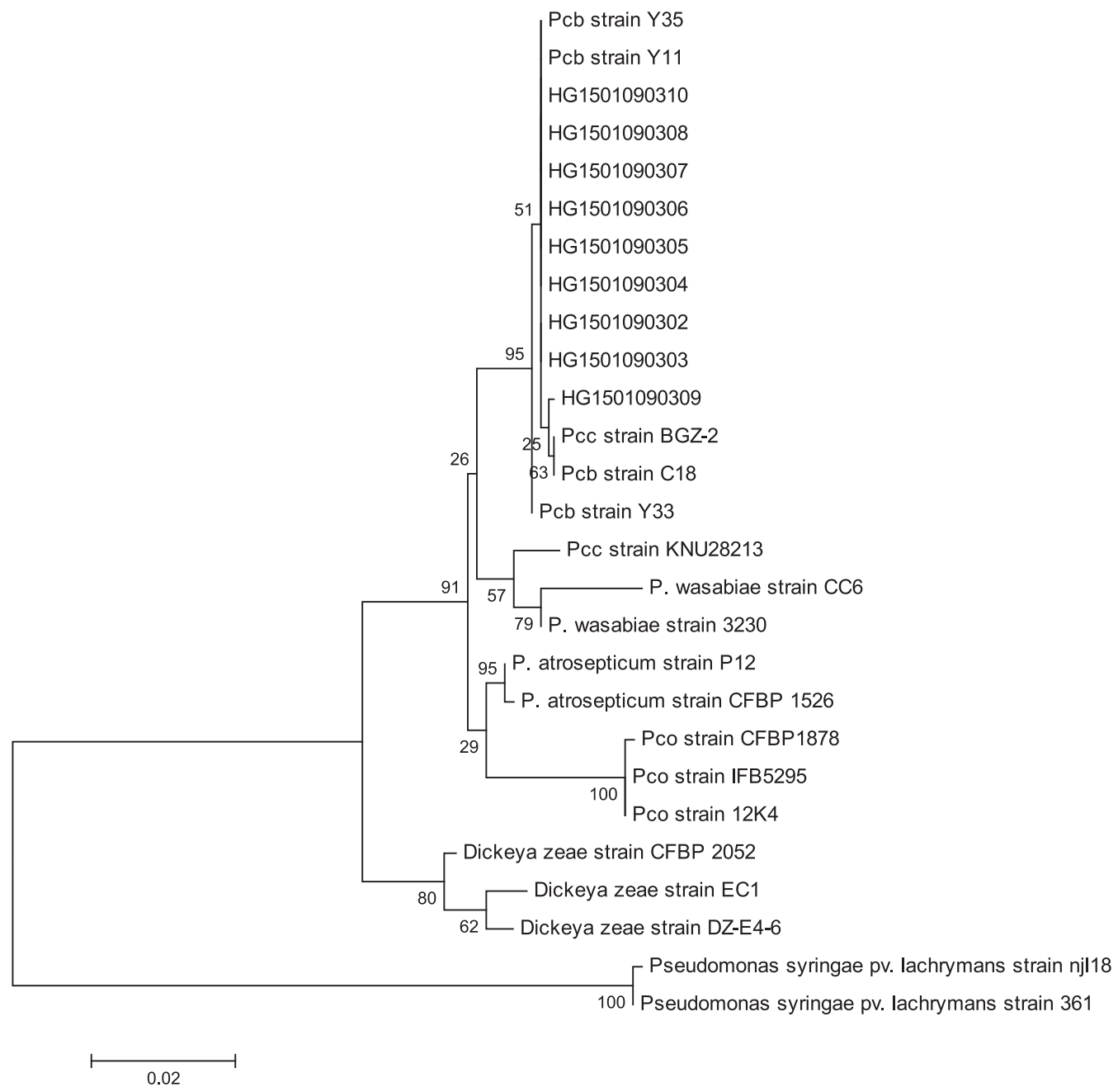

Fig. 2. Phylogenetic relationships among Pectobacterium spp. and Pseudomonas syringae pv. lachrymans using the maximum-likelihood method. Numbers above branches represent bootstrap value support based on maximum-likelihood analyses of 1,000 bootstrap replications. Accession numbers of Pectobacterium spp. and $P$. syringae pv. lachrymans strains are shown in bold font. 
China were clearly assigned to clade II. The P. carotovorum subsp. carotovorum strains also grouped into two clusters (clades III and IV) identified in the previous MLSA study (Nabhan et al. 2011). Strains of $P$. carotovorum subsp. odoriferum were grouped into clade $\mathrm{V}$ and formed a separate homogeneous cluster. These results confirmed that nine selected strains isolated from cucumber in China were different from $P$. carotovorum subsp. carotovorum as well as $P$. carotovorum subsp. odoriferum, and belong to $P$. carotovorum subsp. brasiliense.

Pathogenicity assays. All nine selected strains isolated from cucumber tissues in China were evaluated on their ability to cause soft rot on their original cucumber tissues. Soft rot symptoms were observed on the cucumber seedling stems $24 \mathrm{~h}$ after inoculation (Fig. 4C and D), which is consistent with symptoms observed in field. Symptoms on the cucumber fruit (Fig. 4A and B) and leaves (Fig. $4 \mathrm{E}$ and $\mathrm{F}$ ), which were observed 4 days after inoculation, were consistent with symptoms observed in field. The control seedlings inoculated with sterile water were asymptomatic. Bacteria reisolated from lesions of inoculated tissues exhibited the same traits as the original isolates inoculated.

Host range test. Different host plant species were inoculated with nine randomly selected strains. All the tested strains caused soft rot in species of Brassicaceae (Chinese cabbage, mustard, broccoli, radish, and cabbage), Solanaceae (green pepper, tomato, and potato), spinach, celery, and most Cucurbitaceae (cucumber, zucchini, and watermelon), except for balsam pear and loofah, which belong to the family Cucurbitaceae (Table 1; Fig. 5).

\section{Discussion}

Based on morphology, biochemical and physiological characteristics, and molecular analysis, $P$. carotovorum subsp. brasiliense was identified to cause soft rot diseases on cucumber in Shandong, Shanxi, Hebei, Henan, and Liaoning provinces in China. Cucumber bacterial soft rot is a worldwide, serious bacterial disease on cucumber. During 2014 to 2015, this disease broke out in Shandong, Shanxi, Hebei, Henan, and Liaoning provinces in China, and caused serious economic losses to the local cucumber production. Due to similar symptoms, this disease was previously thought to be caused by Pseudomonas syringae pv. lachrymans. However, this study confirmed that the causal pathogen of cucumber bacterial soft rot in in China was Pectobacterium carotovorum subsp. brasiliense.

Pathogenicity tests showed that the strains isolated from cucumber lesions can cause soft rot in stems and fruit and wet rot on the leaves. Bacterium overflow was also observed on the surface of infected tissues under high humidity. The biochemical and physiological characteristics of the isolate strains are consistent with previous special descriptions for $P$. carotovorum subsp. brasiliense (van der Merwe et al. 2010). The strains reisolated from lesions of inoculated tissues exhibited the same traits as the original isolates inoculated and validated Koch's postulates.

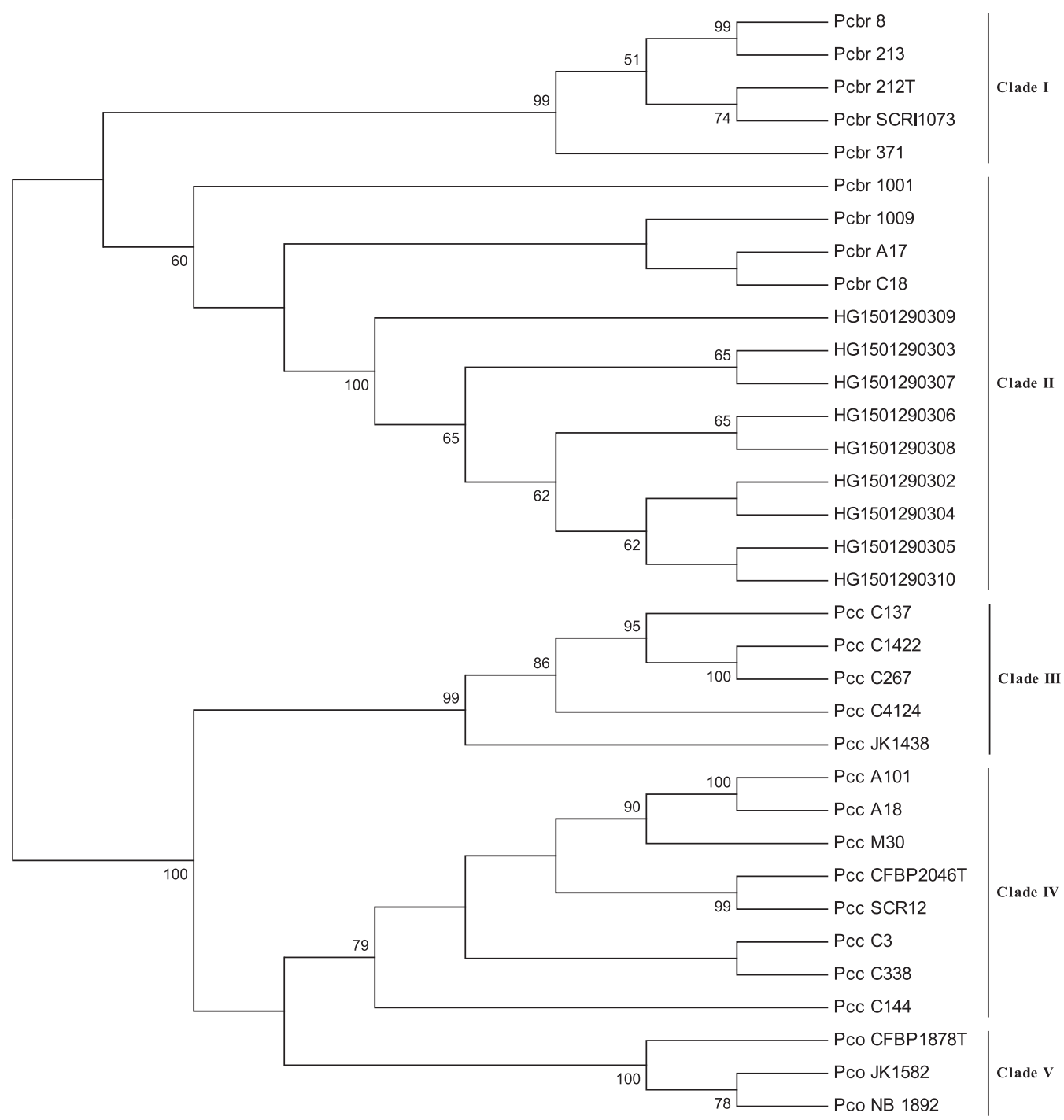

Fig. 3. Phylogenetic reconstruction showing evolutionary relationships among Pectobacterium carotovorum subspecies and isolated strains from cucumber based on multilocus sequence analysis of eight housekeeping gene fragments by the maximum-likelihood method. The bootstrap consensus tree is inferred from 1,000 replicates. There were a total of 3,877 positions in the final data set. Bootstrapping values $<50 \%$ were cut off. 
Based on analysis of the 16S rRNA gene sequence, nine randomly selected strain isolates from cucumber in China are clearly different from Pseudomonas syringae pv. lachrymans but the analysis failed to differentiate them from other Pectobacterium carotovorum strains, which is consistent with the previous study, in which the analysis of partial 16S rRNA gene sequences could not be used to discriminate among the subspecies of Pectobacterium (Nabhan et al. 2012; Naum et al. 2008). Due to the high degree of diversity among subspecies of $P$. carotovorum, MLSA, which has higher sensitivity than DNA hybridization and 16S rRNA gene phylogeny, was employed to differentiate P. carotovorum subspecies (Nabhan et al. 2012). On the basis of our MLSA result, $P$. carotovorum subsp. brasiliense was differentiated as a separate phylogenetic group from $P$. carotovorum subsp. carotovorum and $P$. carotovorum subsp. odoriferum. Strains of $P$. carotovorum subsp. brasiliense grouped into two clades, I and II, and the nine randomly selected strains isolated from cucumber in China were grouped in clade II. Clade II comprised strains from Europe, Asia, and North America. Otherwise, P. carotovorum subsp. carotovorum strains also grouped into two clades, and $P$. carotovorum subsp. odoriferum strains formed a separate homogeneous cluster, assigned to clade $\mathrm{V}$. This confirmed that the strains isolated from cucumber in China were identified as $P$. carotovorum subsp. brasiliense.

The strains grouped in clade II in MLSA spread worldwide and the host plants are not only potato but also other plants (Nabhan et al. 2012). Host range tests showed that, among the candidate plants, all of the plants were infected by the strains isolated from cucumber and showed symptoms of soft rot on stems, except balsam pear and loofah. This result was consistent with published data for $P$. carotovorum subsp. brasiliense (Marquez-Villavicencio et al. 2011), which indicates that the pathogen of cucumber soft rot in China has a wide host range. This characteristic may assist pathogens to survive the harsh environment by parasitizing other plants or plant residues. The surviving pathogens may infect cucumber as the primary source in the next year.

From the results above, through morphology, biochemical and physiological characteristics, 16S rRNA sequence analysis, MLSA, and pathogenicity analysis, we confirmed that the strains isolated from cucumber in China were identified as $P$. carotovorum subsp. brasiliense. As far as we know, this is the first report about P. carotovorum subsp. brasiliense causing cucumber soft rot disease. The disease is expected to have a significant economic impact on cucumber and other crop production.
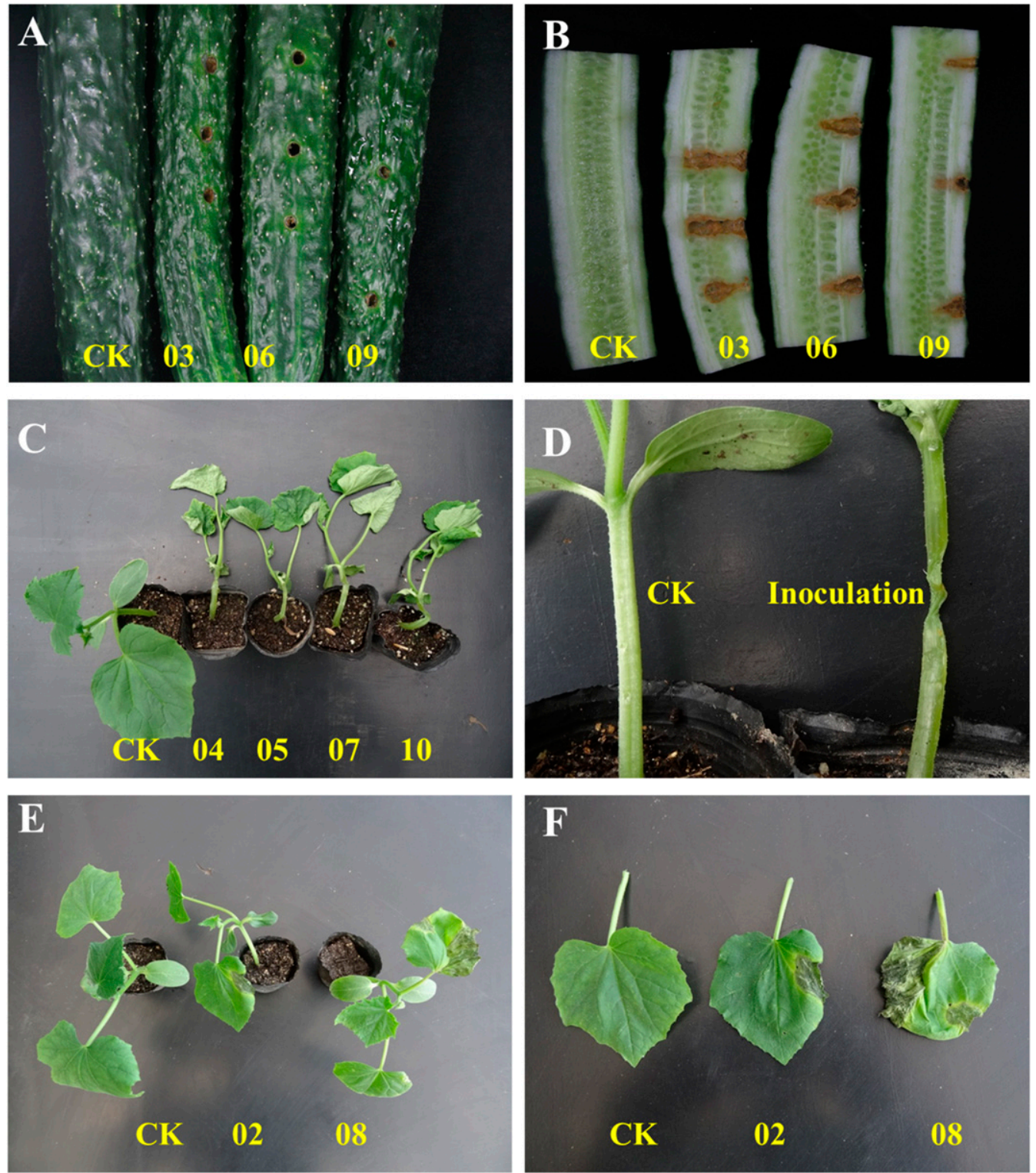

Fig. 4. Effect of the inoculation of Pectobacterium carotovorum subsp. brasiliense strains on $\mathbf{A}$ and $\mathbf{B}$, cucumber fruit; $\mathbf{C}$ and $\mathbf{D}$, stems; and $\mathbf{E}$ and $\mathbf{F}$, leaves of Zhongnong No. 16. $\mathrm{CK}=$ inoculated with sterile water; 03, 06, and 09 = cucumber fruit inoculated with strains of HG1501090303, HG1501090306, and HG1501090309, respectively; 04, 05, 07, and $10=$ cucumber stems inoculated with strains of HG1501090304, HG1501090305, HG1501090307, and HG1501090310, respectively; and 02 and $08=$ cucumber leaves inoculated with strains of HG1501090302 and HG1501090308, respectively. 

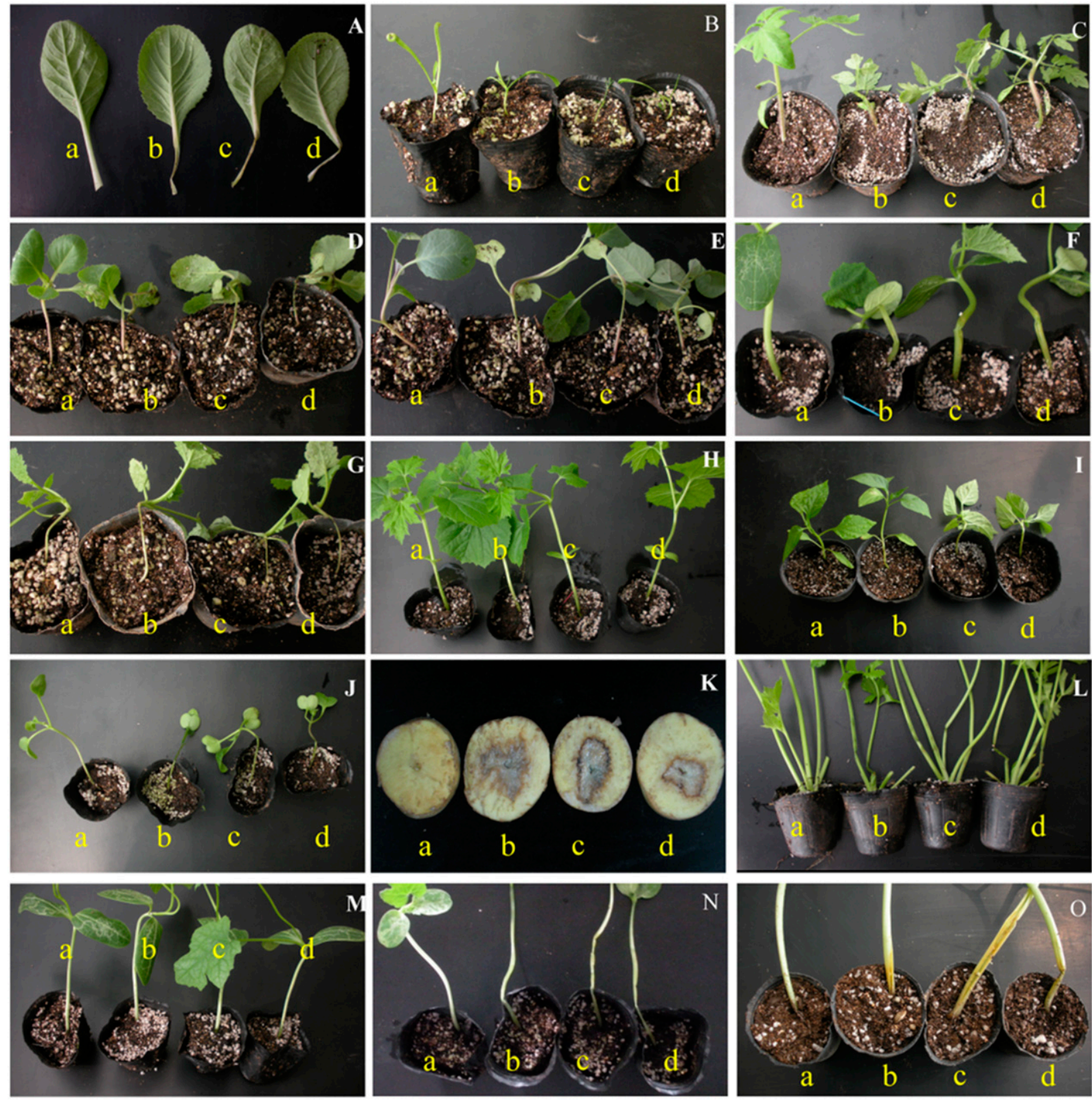

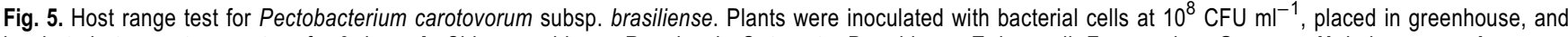
incubated at room temperature for 3 days. A, Chinese cabbage; B, spinach; C, tomato; D, cabbage; E, broccoli; F, cucumber; G, senvy; H, balsam pear; I, pepper J, radish; K, potato; L, celery; M, towel gourd; N, watermelon; and O, pumpkin. Lowercase letters indicate plants inoculated with strains a, HG1501090302; $\mathbf{b}$ HG1501090303; and $\mathbf{c}$ and d, HG1501090304.

\section{Acknowledgments}

This work was supported by the Science and Technology Innovation Program of the Chinese Academy of Agricultural Sciences (CAAS-ASTIPIVFCAAS) and the Key Laboratory of Biology and Genetic Improvement of Horticultural Crops, Ministry of Agriculture, P.R. China; and was funded by Modern Agro-Industry Technology Research System in China (CARS-25)

\section{Literature Cited}

Choi, O., and Kim, J. 2013. Pectobacterium carotovorum subsp. brasiliense causing soft rot on paprika in Korea. J. Phytopathol. 161:125-127.

de Werra, P., Bussereau, F., Keiser, A., and Ziegler, D. 2015. First report of potato blackleg caused by Pectobacterium carotovorum subsp. brasiliense in Switzerland. Plant Dis. 99:551.

Duarte, V., De Boer, S. H., Ward, L. J., and de Oliveira, M. C. 2004. Characterization of atypical Erwinia carotovora strains causing blackleg of potato in Brazil. J. Appl. Microbiol. 96:535-545.

Gallois, A., Samson, R., Ageron, E., and Grimont, P. A. D. 1992. Erwinia carotovora subsp. odorifera subsp. nov., associated with odorous soft rot of chicory (Cichorium intybus L.). Int. J. Syst. Bacteriol. 42:582-588.
Gardan, L., Gouy, C., Christen, R., and Samson, R. 2003. Elevation of three subspecies of Pectobacterium carotovorum to species level: Pectobacterium atrosepticum sp. nov., Pectobacterium betavasculorum sp. nov. and Pectobacterium wasabiae sp. nov. Int. J. Syst. Evol. Microbiol. 53:381-391.

Hanage, P. W., Fraser, C., and Spratt, B. G. 2006. Sequences, sequence clusters and bacterial species. Philos. Trans. R. Soc. B 361:1917-1927.

Hauben, L., Moore, E. R., Vauterin, L., Steenackers, M., Mergaert, J., Verdonck, L., and Swings, J. 1998. Phylogenetic position of phytopathogens within the Enterobacteriaceae. Syst. Appl. Microbiol. 21:384-397.

Kim, H. S., Ma, B., Perna, N. T., and Charkowski, A. O. 2009. Phylogeny and virulence of naturally occurring type III secretion system-deficient Pectobacterium strains. Appl. Environ. Microbiol. 75:4539-4549.

Ma, B., Hibbing, M. E., Kim, H.-S., Reedy, R. M., Yedidia, I., Breuer, J., Breuer, J., Glasner, J. D., Perna, N. T., Kelman, A., and Charkowski, A. O. 2007. Host range and molecular phylogenies of the soft rot enterobacterial genera Pectobacterium and Dickeya. Phytopathology 97:1150-1163.

Marquez-Villavicencio, M. P., Groves, L. R., and Charkowski, O. A. 2011. Soft ro disease severity is affected by potato physiology and Pectobacterium taxa. Plant Dis. 95:232-241.

Nabhan, S., Boer, S. H. D., Maiss, E., and Wydra, K. 2012. Taxonomic relatedness between Pectobacterium carotovorum subsp. carotovorum, Pectobacterium 
carotovorum subsp. odoriferum and Pectobacterium carotovorum subsp. brasiliense subsp. nov. J. Appl. Microbiol. 113:904-913.

Nabhan, S., Wydra, K., Linde, M., and Debener, T. 2011. The use of two complementary DNA assays, AFLP and MLSA, for epidemic and phylogenetic studies of pectolytic enterobacterial strains with focus on the heterogeneous species Pectobacterium carotovorum. Plant Pathol. 61:498-508.

Naum, M., Brown, E. W., and Mason-Gamer, R. J. 2008. Is 16s rDNA a reliable phylogenetic marker to characterize relationships below the family level in the Enterobacteriaceae. J. Mol. Evol. 66:630-642.

Onkendi, E. M., Maluleke, L. N., and Moleleki, L. N. 2014. First report of Pectobacterium carotovorum subsp. brasiliense causing soft rot and blackleg of potatoes in Kenya. Plant Dis. 98:684-685.

Panda, P., Fiers, M. A. W. J., Armstrong, K., and Pitman, A. R. 2012. First report of blackleg and soft rot of potato caused by Pectobacterium carotovorum subsp. brasiliensis in New Zealand. New Dis. Rep. 26:15.

Pérombelon, M. C. M. 2002. Potato disease caused by soft rot Erwinias: An overview of pathogenesis. Plant Pathol. 51:1-12.
Pérombelon, M. C. M., and Kelman, A. 1980. Ecology of the soft rot Erwinias. Annu. Rev. Phytopathol. 18:361-387.

Tamura, K., and Nei, M. 1993. Estimation of the number of nucleotide substitutions in the control region of mitochondrial DNA in humans and chimpanzees. Mol. Biol. Evol. 10:512-526.

Tamura, K., Peterson, D., Peterson, N., Stecher, G., Nei, M., and Kumar, S. 2011. MEGA5.05: Molecular evolutionary genetics analysis using maximum likelihood, evolutionary distance, and maximum parsimony methods. Mol. Biol. Evol. 28: 2731-2739.

Toth, I. K., Bell, K. S., Holeva, M. C., and Birch, P. R. J. 2003. Soft rot Erwiniae: From genes to genomes. Mol. Plant Pathol. 4:17-30.

van der Merwe, J. J., Coutinho, T. A., Korsten, L., and van der Waals, J. 2010 Pectobacterium carotovorum subsp. brasiliensis causing blackleg on potatoes in South Africa. Eur. J. Plant Pathol. 126:175-185.

Waleron, M., Waleron, K., and Łojkowska, E. 2002. Genotypic characterization of the Erwinia genus by PCR-RFLP analysis of rpoS gene. Plant Prot Sci. 38 288-290. 